\title{
Effect of Metabolic Clearance Rate and Hepatic Extraction of Insulin on Hepatic and Peripheral Contributions to Hypoglycemia
}

Zvi Chap, Toshihiko Ishida, Jesse Chou, Craig J. Hartley, Robert M. Lewis, Mark Entman, and James B. Field

Diabetes Research Center, St. Luke's Episcopal Hospital, Baylor College of Medicine, Department of Medicine, Division of Endocrinology and Metabolism, and Section of Cardiovascular Sciences, Department of Medicine, Baylor College of Medicine

\begin{abstract}
Effects of alterations in metabolic clearance rates, hepatic extraction, and plasma concentrations of insulin on hepatic and peripheral contribution to hypoglycemia and glucose counterregulation were studied in conscious dogs. Since insulin and sulfated insulin had markedly different metabolic clearance rates $(34 \pm 1 \mathrm{vs} .16 \pm 1 \mathrm{ml} / \mathrm{kg}$ per $\mathrm{min}$, respectively) and fractional hepatic extraction $(42 \pm 1 \%$ vs. $15 \pm 2 \%$, respectively), biologically equivalent amounts infused intraportally produced twofold higher hepatic vein and artery sulphated insulin concentrations and concentrations that were $30 \%$ higher in the portal vein. This significantly larger arterial/portal concentration ratio (0.67 vs. 0.45, respectively) permitted assessment of differential distribution of insulin on glucose turnover using $\left[3-{ }^{3} \mathrm{H}\right]$ glucose. Insulin and sulfated insulin (1 and $2 \mathrm{mU} / \mathrm{kg}$ per min) caused similar hypoglycemia. While insulin transiently suppressed glucose production and increased glucose disappearance, sulfated insulin had significantly greater effects on glucose disappearance and clearance, without suppression of glucose production. Despite similar hypoglycemia, sulfated insulin caused greater increment in glucagon. $3 \mathrm{mU} / \mathrm{kg}$ per min insulin caused more rapid and greater hypoglycemia, greater glucose clearance, and greater glucagon increments without suppression of glucose production, which indicates that with larger doses of insulin counterregulation can absolutely mask the suppressive effect of insulin.

The effects of insulin and sulfated insulin were evaluated using euglycemic clamp to eliminate interference from stimulated counterregulation. Sequential infusion of 1 and $2 \mathrm{mU} / \mathrm{kg}$ per min of both insulins suppressed endogenous glucose production to 0 at $150 \mathrm{~min}$, which indicates that the apparent lack of a hepatic effect of sulfated insulin during hypoglycemia was masked by greater counterregulation. This greater counterregulation may reflect greater peripheral glucose clearance, and prevented greater hypoglycemia than after the same insulin doses. The results indicate that the different rates of removal and the total metabolic clearance rate caused different concentrations and relative distribution between the portal and arterial blood compartments, leading to the significantly different contributions by the liver and peripheral tissues to the same hypoglycemia.
\end{abstract}

Address correspondence to Dr. Field, St. Luke's Episcopal Hospital, Diabetes Research Laboratory, P.O. Box 20269, Houston, TX 77225. Dr. Ishida's current address is Kagawa Medical School, 1750-1, Miki-cho, Kita-Gun, Kagawa 76107, Japan.

Received for publication 14 November 1984 and in revised form 26 August 1985.

J. Clin. Invest.

(C) The American Society for Clinical Investigation, Inc. $0021-9738 / 85 / 12 / 2222 / 13 \quad \$ 1.00$

Volume 76, December 1985, 2222-2234

\section{Introduction}

The liver is a major site of uptake, degradation, and biologic action of insulin. It is not known, however, whether all of the hormone extracted by that organ exerts a biological effect or whether extraction may be independent of any physiological action. In addition, the rate of hepatic extraction affects peripheral levels of the hormone. The effects of insulin on glucose utilization (peripheral effect) and suppression of glucose production (hepatic effect) are dose-related processes with different sensitivities and insulin saturating levels (1). On this basis we evaluated the effects of differences in fractional hepatic extraction of insulin with its resulting change in the concentrations and relative distribution of the hormone between the portal vein (predominantly hepatic effect) and arterial (peripheral effect) blood compartments. Such alterations may produce different contributions by the liver and peripheral tissues to the ensuing hypoglycemia. Since hypoglycemia triggers counterregulatory hormone secretion, which increases glucose production (2-7), this may modify the effect of insulin on hepatic glucose production. To examine these questions we compared insulin and sulfated insulin, which has markedly lower hepatic extraction, on the mechanism of hypoglycemia. This involved measurements of their effects on glucose levels, appearance, disappearance, and clearance, and the counterregulatory responses of glucagon. Their binding to liver plasma membranes and these various interrelationships were also examined.

Our data indicate that the significantly lower hepatic extraction of sulfated insulin caused higher concentrations of the hormone and significantly different relative distribution between the portal vein and arterial blood compartments. This results in significantly different contributions by the liver and peripheral tissues to the same hypoglycemia and was associated with greater counterregulatory effect on glucose production.

\section{Methods}

\section{Materials}

Regular insulin (Regular Iletin I, $25 \mathrm{U} / \mathrm{mg}$, was kindly supplied by Eli Lilly \& Co., Indianapolis, IN, and sulfated insulin $(5.75 \mathrm{U} / \mathrm{mg})$ was generously provided by Connaught Laboratories, Willowdale, Ontario, Canada.

\section{Animals and surgery}

Healthy, adult male and female dogs weighing 20-30 kg were prepared with chronically implanted catheters in the portal and hepatic veins and carotid artery and Doppler flow probes on the portal vein and hepatic artery as previously described (8). Regular or sulfated insulin was infused into the portal system through a catheter placed in the superior mesenteric vein. A catheter for the infusion of $\left[3-{ }^{3} \mathrm{H}\right]$ glucose was inserted into the external jugular vein.

\section{Experimental procedures}

After at least 2 wk recovery from surgery, experiments were done after an 18-h fast in conscious, unrestrained dogs. Experiments were done 
only in dogs whose hematocrits were over $30 \%$, who appeared to be in healthy condition, had good appetites, and had normal stools. The blood pressure, which was measured continuously with a Statham P23db pressure transducer connected to the arterial catheter, did not change significantly throughout each experiment. Blood samples for glucose, glucose specific activity, insulin, and glucagon were taken simultaneously from the portal vein, hepatic vein, and carotid artery with continuous measurements of the portein vein and hepatic artery blood flows that did not change significantly throughout the experiment and were similar in all the experimental groups. Blood was collected into chilled tubes containing $500 \mathrm{U}$ Trasylol (Mobay Chemical Corp., New York, NY) and $1.2 \mathrm{mg}$ EDTA $/ \mathrm{ml}$ of blood. For isotopic determination of glucose appearance, disappearance, and clearance rates, a priming dose $(48 \mu \mathrm{Ci})$ of $\left[3-{ }^{3} \mathrm{H}\right]$ glucose (New England Nuclear, Boston, MA; specific activity, $12.3 \mathrm{C} / \mathrm{mmol}$ ) was administered at $-150 \mathrm{~min}$ followed by infusion of $0.4 \mu \mathrm{Ci} / \mathrm{min}$ during a 150 -min equilibration period and 180 -min experimental period. The coefficient of variation of glucose specific activity during the final 30 -min equilibration period (four samples) was $2.1 \pm 0.5 \%$ (mean \pm SEM).

\section{Experimental protocols}

Protocol I (insulin) and protocol II (sulfated insulin). After a 30-min control period, biologically equivalent amounts of either sulfated insulin $(n=7)$ or regular insulin $(n=9)$ were infused into the superior mesenteric vein $(1 \mathrm{mU} / \mathrm{kg}$ per min from 0 to $75 \mathrm{~min}$ and $2 \mathrm{mU} / \mathrm{kg}$ per min from 75 to $150 \mathrm{~min}$ ) using a multispeed transmission infusion pump (Harvard Apparatus Co., Natick, MA). The infusion rates were chosen to increase insulin levels in the physiological range. Blood samples were obtained at $-30,-20,-10,0,15,30,45,60,75,90,105,120,135,150,165$, and $180 \mathrm{~min}$. These experiments provided determination of hepatic extraction of the hormones and the measurement of glucose kinetics.

Protocol III. After a 30-min control period, insulin was infused intraportally $(n=6)$ at a rate of $3 \mathrm{mU} / \mathrm{kg}$ per min from 0 to $120 \mathrm{~min}$. This dose was used to examine whether higher levels of insulin and greater hypoglycemia can mask its effect on hepatic glucose production. Blood samples were obtained at $-30,-20,-10,0,15,30,45,60,75$, $90,105,120,135$, and $150 \mathrm{~min}$. Insulin and glucagon were measured in this group in the portal vein and carotid artery.

Protocol IV. After a 30-min control period, sulfated insulin was infused into the portal system at $0.25 \mathrm{mU} / \mathrm{kg}$ per min from 0 to $75 \mathrm{~min}$ and $0.5 \mathrm{mU} / \mathrm{kg}$ per min from 75 to $150 \mathrm{~min}$ or $0.5 \mathrm{mU} / \mathrm{kg}$ per min from 0 to $75 \mathrm{~min}$ and $1 \mathrm{mU} / \mathrm{kg}$ per min from 75 to $150 \mathrm{~min}$. This dose of sulfated insulin was used to examine whether lower peripheral levels of the hormones will result in net suppression of glucose production. Blood samples from the carotid artery only were obtained as in protocols I and II.

Protocol $V$. After a 30-min control period, insulin $(n=7)$ or sulfated insulin $(n=6)$ were infused at the same rates as in protocols I and II. However, hypoglycemia was prevented using a euglycemic clamp (each dog at its own basal glucose level), by infusion of appropriate amounts of dextrose (5\%) into the external jugular vein. Adjustment of the glucose infusion rates was based upon plasma glucose determinations every 5 min. The infusion of exogenous glucose was stopped simultaneously with the termination of the hormone infusion. Arterial blood samples were obtained as in protocols I and II.

\section{Analysis}

Plasma glucose concentration was measured by the glucose oxidase method with a Beckman glucose analyzer (Beckman Instruments, Inc., Fullerton, CA). The specific activity of $\left[3-{ }^{3} \mathrm{H}\right]$ glucose was measured as previously reported, utilizing plasma deproteinized by the Somogyi method (9). Correction for quenching was made by using the method of external standard ratio. The glucose specific activity of each plasma sample was calculated by dividing the glucose radioactivity by its glucose concentration.

Plasma immunoreactive insulin was measured by radioimmunoassay using a guinea pig anti-insulin antiserum, purified porcine insulin standard, and ${ }^{125} \mathrm{I}$-labeled pork insulin tracer, and a dextran-coated charcoal separation technique (10). Although the minimum sensitivity of the assay was $>6.25 \mu \mathrm{U} / \mathrm{ml}$, all of the experimental values exceeded this amount. Plasma-sulfated insulin was determined using the above assay and sulfated insulin standards. A comparison of the standard curves obtained with insulin and sulfated insulin is shown in Fig. 1. Although the binding of the sulfated insulin to the antibody was less than that of insulin, adequate sensitivity is maintained for the accurate measurement of this modified insulin. The inter-assay and intra-assay coefficients of variation for sulfated insulin and insulin are $\pm 11.4 \%$ and $\pm 3.1 \%$, and $10.1 \%$ and $1.6 \%$, respectively, at a concentration of $50 \mu \mathrm{U} / \mathrm{ml}$. The validity of this radioimmunoassay for sulfated insulin was also established by Nomura et al. (11). Plasma immunoreactive glucagon was assayed with Unger's $30 \mathrm{~K}$ antibody (12).

The blood flow measurements utilized an ultrasonic range-gated pulsed Doppler flow meter designed by Hartley et al. $(13,14)$ and described in detail previously (8).

\section{Calculations}

Endogenous glucose appearance and disappearance during the control period was calculated over $10-\mathrm{min}$ periods during the basal state by the isotope-dilution equation: turnover rate $=F / S A_{E}$, where $F$ is the infusion rate of tritiated glucose $(\mathrm{Ci} / \mathrm{kg}$ per $\mathrm{min})$ and $\mathrm{SA}_{\mathrm{E}}$ is the specific activity of plasma glucose at equilibrium ( $\mathrm{nCi} / \mathrm{mg}$ ). In the nonsteady state after hormone infusion, rates of glucose appearance and disappearance ( $\mathrm{mg} /$ $\mathrm{kg}$ per $\mathrm{min}$ ) were calculated over 15 -min periods employing the equation of Steele (15) as modified by DeBodo et al. (16). The rapidly equilibrating pool fraction was assumed to be $0.65(15,17)$. Glucose clearance $(\mathrm{ml} /$ $\mathrm{kg}$ per $\mathrm{min}$ ) was calculated as the ratio of the rate of glucose disappearance and plasma glucose concentrations and was normalized to body weight. The use of $\left[3-{ }^{3} \mathrm{H}\right]$ glucose as a nonrecycling tracer has been discussed in detail (18). During the euglycemic clamp, total glucose appearance was obtained by the radioisotopic determination $(15,16)$. Since the total glucose appearance is the sum of the amount of glucose infused and the residual endogenous glucose production, the latter was obtained by subtracting the amount infused from the total glucose appearance (all expressed in $\mathrm{mg} / \mathrm{kg}$ per $\mathrm{min}$ ).

The blood flow measurements were corrected to plasma flow based on hematocrits obtained every $30 \mathrm{~min}$, since insulin was measured in plasma. The flux of insulin in each vessel, the fractional hepatic extraction, and the metabolic clearance rate were determined as previously reported $(8,19)$. Calculation of the mean value of the hepatic extraction of hormone was based on the percentage of hormone extracted in each individual dog and not the mean amounts of hormone reaching and leaving the liver.

\section{Insulin binding assay}

Partially purified plasma membrane fractions of liver from rats were prepared as previously described $(20,21)$. Porcine ${ }^{125} \mathrm{I}$-insulin (New England Nuclear, Boston, MA) at a specific activity of $105 \mu \mathrm{Ci} / \mu \mathrm{g}$ was used for the binding assay. The binding assay was performed as previously

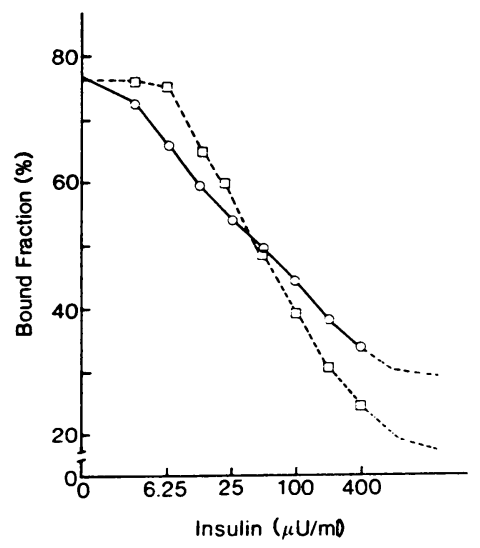

Figure 1. Typical binding curves for sulfated insulin $(0)$ and insulin ( $\square$ ) in the radioimmunoassay described in Methods. 
described $(22,23)$. The binding of ${ }^{125} \mathrm{I}$-insulin $(0.2 \mathrm{ng} / \mathrm{ml}$ in all tubes) to liver membrane fraction $(0.2 \mathrm{mg}$ membrane protein $/ \mathrm{ml})$ was done in triplicate in microfuge tubes (Beckman Instruments, Inc.) at $20^{\circ} \mathrm{C}$ for 6 h. Unlabeled insulin and sulfated insulin were added in a range of $0.17-$ $167 \mathrm{pmol} / \mathrm{ml}$ and $0.74-740 \mathrm{pmol} / \mathrm{ml}$, respectively. The concentrations in terms of biologic potency were equal $(0.026-25.6 \mathrm{mU} / \mathrm{ml})$ for both insulins. ${ }^{125} \mathrm{I}$-insulin, unlabeled insulin, and liver plasma membranes (in this order) were added in $50-\mu$ l aliquots each in Krebs-Ringer phosphate buffer, $\mathrm{pH}$ 7.5. The aliquot of the radioactive insulin contained $30 \mathrm{mg} /$ $\mathrm{ml}$ serum albumin. During the incubation the tubes were agitated for 2 $s$ each hour. At the end of the incubation the tubes were transfered to an ice water bath and centrifuged for $2 \mathrm{~min}$ in a microfuge (Beckman Instruments, Inc.). The supernatant was aspirated and discarded. Additional washing of the pellet was done with $0.3 \mathrm{ml}$ Krebs-Ringer buffer containing $10 \%$ sucrose. The tips of the tubes that contained the pellet of membranes were excised and counted in a gamma counter. Nonspecific binding, defined as the radioactivity associated with the membrane pellet in the presence of $50 \mu \mathrm{g} / \mathrm{ml}$ unlabeled insulin, was $<10 \%$ of the total binding and was subtracted from total binding to yield specific binding. Membrane protein concentrations were determined by the Lowry technique (24) and the observed specific binding was normalized to $0.2 \mathrm{mg}$ membrane protein $/ \mathrm{ml}$.

\section{Statistics}

The data are presented as mean \pm SEM. The basal value was the mean \pm SEM of the four values obtained during the control period $(-30$ to $0 \mathrm{~min}$ ). One-way analysis of variance and one repeated measure was employed to analyze the changes from basal value within a group. Differences in mean values between groups were detected by two-way analysis of variance and one repeated measure. $P$ values less than 0.05 were considered to be significant.

\section{Results}

Plasma glucose levels (protocols I and II). Before infusion of insulin or sulfated insulin, plasma glucose levels were similar in both groups $(76 \pm 4$ and $78 \pm 3 \mathrm{mg} / 100 \mathrm{ml}$, respectively, Fig. 2 $A$ ). After infusion of both insulins, glucose concentrations decreased significantly below basal by $15 \mathrm{~min}$ and reached a nadir of $41-43 \mathrm{mg} / 100 \mathrm{ml}$ at $120-150 \mathrm{~min}$. At no time were the plasma glucose concentrations significantly different between the two groups. The total decrement of glucose level (area below basal level) was $4,192 \pm 363 \mathrm{mg} / \mathrm{dl}$ per $3 \mathrm{~h}$ after insulin and 4,363 \pm 393 $\mathrm{mg} / \mathrm{dl}$ per $3 \mathrm{~h}$ after sulfated insulin (Fig. $2 \mathrm{~A}$ ). Expressed as percent decrease from the extended basal level to $180 \mathrm{~min}$, those decrements were identical $(31 \pm 2 \%$; see also Table I).

Glucose turnover (protocol I and protocol II). During the control period, glucose appearance was $2.9 \pm 0.2 \mathrm{mg} / \mathrm{kg}$ per min in the insulin group, which is not significantly different from the $3.3 \pm 0.3 \mathrm{mg} / \mathrm{kg}$ per min measured in the sulfated group (Fig. 2 $B$ ). Infusion of insulin significantly decreased glucose appearance below basal values from 30 to $75 \mathrm{~min}$ with a nadir of $1.7 \pm 0.3$ $\mathrm{mg} / \mathrm{kg}$ per min. After returning to basal at $90 \mathrm{~min}$, it progressively increased and was significantly above basal at $180 \mathrm{~min}$. In contrast, sulfated insulin did not decrease glucose appearance but tended to increase it as early as $15 \mathrm{~min}$ and significantly so at 150,165 , and $180 \mathrm{~min}$. Furthermore, the increases in glucose appearance after sulfated insulin usually significantly exceeded that after insulin. Glucose disappearance during the control period was similar to glucose appearance (Fig. $2 C$ ). Sulfated insulin caused rapid and significant increase in glucose disappearance that was maintained throughout the experiment. Although insulin also increased glucose disappearance, it was delayed and not significantly above basal. Glucose disappearance was significantly greater after sulfated insulin. Basal glucose clearance was similar in both groups and increased significantly above basal values with the infusion of both insulins (Fig. 2 D). However, the effect was significantly earlier and greater after sulfated insulin. The total increment in glucose clearance (area above
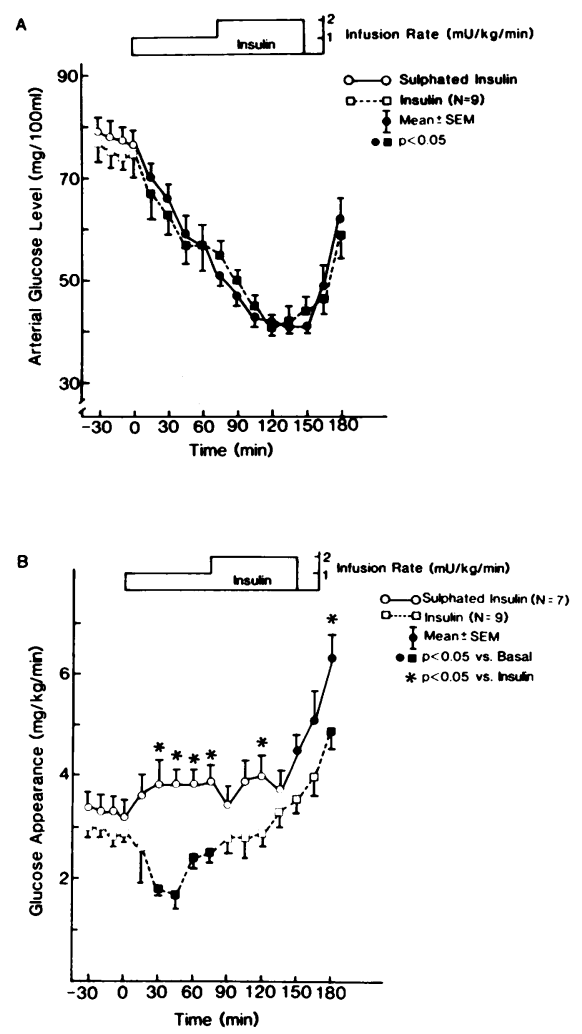
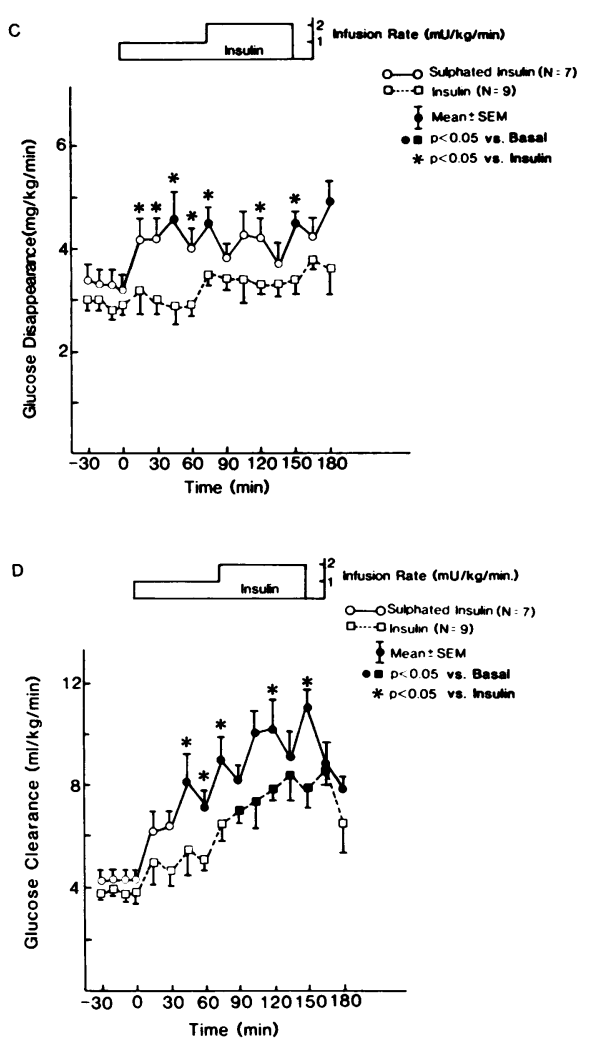

Figure 2. Comparison of the effects of sulfated insulin (O) and insulin ( $\square$ ) infused at 1 and $2 \mathrm{mU} / \mathrm{kg}$ per $\mathrm{min}$ on glucose levels $(A)$; glucose appearance $(B)$; glucose disappearance $(C)$; and glucose clearance $(D)$. Closed symbols represent significant difference from basal values $(P<0.05)$. Asterisks indicate significant difference between effects of sulfated insulin and insulin. 
Table I. Arterial Insulin Levels, Glucose Decrements, Glucose Clearance, and Glucagon Incremental Areas After Different Doses of Sulfated Insulin and Insulin Infusions

\begin{tabular}{llclll}
\hline & \multicolumn{2}{l}{ Arterial insulin } & & Glucose clearance \\
Hormone infusion rate & $0-75 \mathrm{~min}$ & $75-150 \mathrm{~min}$ & $\begin{array}{l}\text { Glucose decremental } \\
\text { area below basal }\end{array}$ & $\begin{array}{l}\text { Glucremental area } \\
\text { above basal }\end{array}$ & $\begin{array}{l}\text { Glucagon incremental } \\
\text { area above basal }\end{array}$ \\
\hline$m U / k g$ per $\mathrm{min}$ & $\mu U / \mathrm{ml}$ & $\mu U / \mathrm{ml}$ & percent & percent & percent \\
$0.25-0.5$ (S-I) & $15 \pm 1$ & $32 \pm 1$ & $16 \pm 4$ & $33 \pm 6$ & - \\
$0.5-1.0(\mathrm{~S}-\mathrm{I})$ & $34 \pm 1$ & $59 \pm 1$ & $26 \pm 2$ & $69 \pm 12$ & $129 \pm 43$ \\
$1.0-2.0$ (S-I) & $63 \pm 3$ & $122 \pm 4$ & $31 \pm 2$ & $102 \pm 11$ & $235 \pm 58$ \\
$1.0-2.0$ (I) & $30 \pm 1$ & $59 \pm 2$ & $31 \pm 2$ & $67 \pm 8$ & $119 \pm 27$ \\
$3.0(\mathrm{I})$ & $83 \pm 3$ & $83 \pm 3$ & $38 \pm 3$ & $123 \pm 12$ & $247 \pm 94$
\end{tabular}

S-I, sulfated insulin; I, insulin. The decremental and incremental areas were expressed as percent change compared with the extended basal level over the entire experimental periods. Data are given as mean \pm SEM.

basal values) was $767 \pm 68 \mathrm{ml} / \mathrm{kg}$ per $3 \mathrm{~h}$ after sulfated insulin and $466 \pm 58 \mathrm{ml} / \mathrm{kg}$ per $3 \mathrm{~h}(P<0.005)$ after insulin. Compared as percent increase above the extended basal levels in each group, glucose clearance increased by $102 \pm 11 \%$ (sulfated insulin) compared with $67 \pm 8 \%$ (insulin) $(P<0.025)$.

Plasma insulin levels and balance across the liver (protocol $I$ and protocol II). Control portal vein insulin levels $(23 \pm 3 \mu \mathrm{U} /$ $\mathrm{ml}$ and $29 \pm 7 \mu \mathrm{U} / \mathrm{ml}$ ) were similar in both groups and significantly exceeded the hepatic vein and arterial insulin levels (Fig. $3 A$ and $B$ ). Portal vein insulin significantly increased to an average of $76 \pm 1 \mu \mathrm{U} / \mathrm{ml}$ during infusion of $1 \mathrm{mU} / \mathrm{kg}$ per min insulin. Hepatic vein and arterial insulin levels plateaued at an average of $35 \pm 2$ and $30 \pm 1 \mu \mathrm{U} / \mathrm{ml}$, respectively. Insulin infusion at $2 \mathrm{mU} / \mathrm{kg}$ per min increased portal vein, hepatic vein, and arterial insulin concentrations to $134 \pm 2,69 \pm 1$, and $59 \pm 2 \mu \mathrm{U} /$ $\mathrm{ml}$, respectively (Fig. $3 A$ ). Sulfated insulin levels increased significantly more than regular insulin to average concentrations of $106 \pm 4 \mu \mathrm{U} / \mathrm{ml}$ in the portal vein, $77 \pm 2 \mu \mathrm{U} / \mathrm{ml}$ in the hepatic vein, and $63 \pm 3 \mu \mathrm{U} / \mathrm{ml}$ in the artery during the first period (0$75 \mathrm{~min})$. During the second period of infusion $(75-150 \mathrm{~min})$ the sulfated insulin average concentrations were $165 \pm 5 \mu \mathrm{U} / \mathrm{ml}$ in the portal vein, $135 \pm 3 \mu \mathrm{U} / \mathrm{ml}$ in the hepatic vein, and $122 \pm 4$ $\mu \mathrm{U} / \mathrm{ml}$ in the artery (Fig. $3 \mathrm{~B}$ ). After termination of the infusion, arterial plasma insulin decreased more gradually after the infusion of sulfated insulin and was significantly higher at $37 \pm 5$ $\mu \mathrm{U} / \mathrm{ml}$ compared with $12 \pm 2 \mu \mathrm{U} / \mathrm{ml}$ after insulin at the end of the experiment.

The basal amount of insulin presented to and leaving the
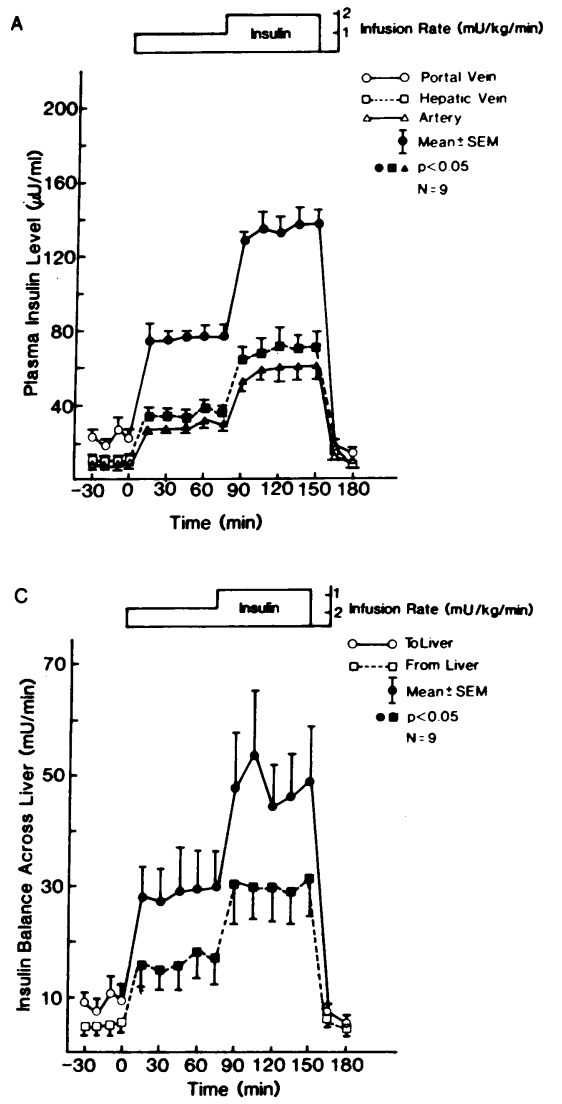
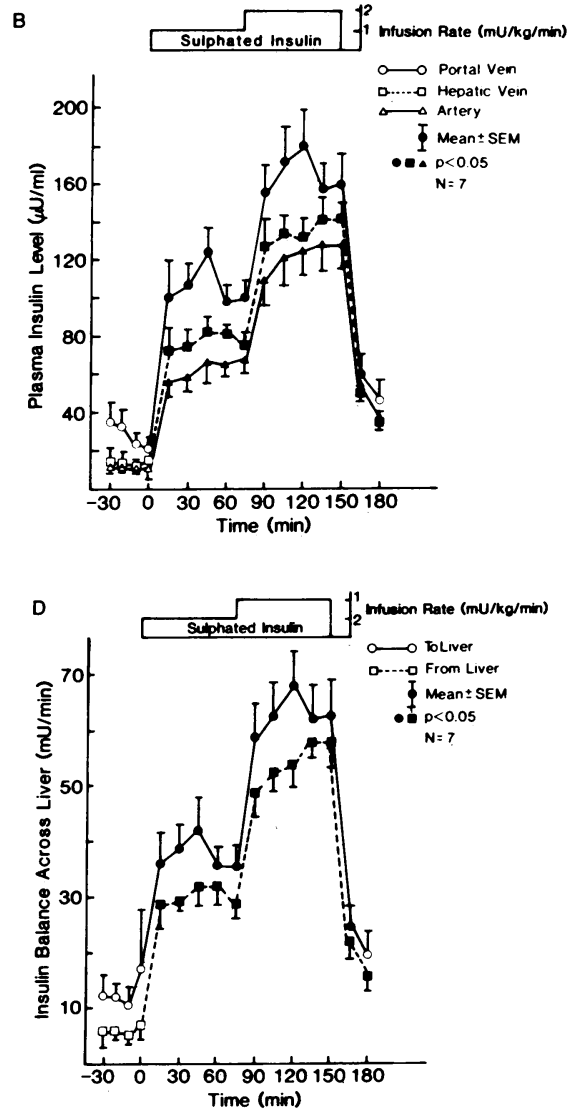

Figure 3. Plasma insulin levels of portal vein (O), hepatic vein $(\square)$, and artery $(\Delta)$, after the infusion at 1 and $2 \mathrm{mU} /$ kg per min of insulin $(A)$ or sulfated insulin $(B)$. The amounts of insulin $(C)$ and sulfated insulin $(D)$ delivered to $(O)$, and from ( $\square$ ) the liver. Closed symbols indicate significant difference from basal values. 

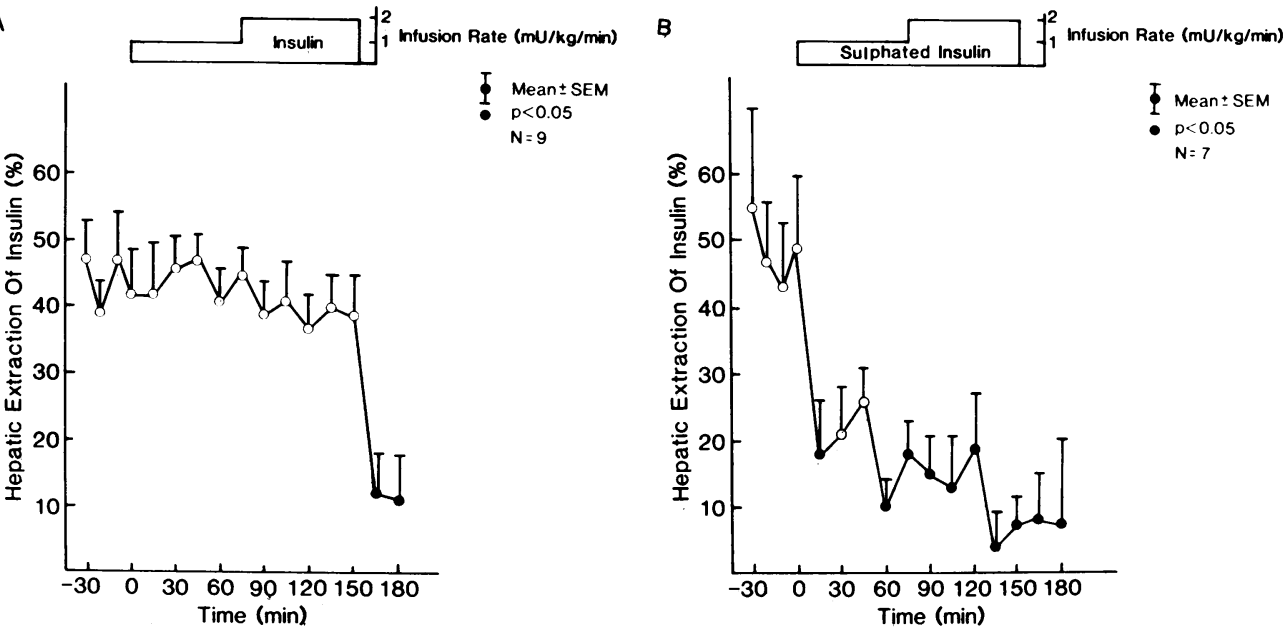

Figure 4. The fractional hepatic extractions of insulin $(A)$ and sulfated insulin $(B)$ after their infusion into the portal system. Closed symbols represent significant difference from basal values.

liver was similar in the two groups (Fig. $3 C$ and $D$ ). During the first period of infusion, insulin presented to the liver increased to $29 \pm 1 \mathrm{mU} / \mathrm{min}$ as compared with $37 \pm 1 \mathrm{mU} / \mathrm{min}$ of sulfated insulin (28\% more than after insulin). Infusion of $2 \mathrm{mU} / \mathrm{kg}$ per min increased the amount of insulin $(48 \pm 2 \mathrm{mU} / \mathrm{min})$ reaching the liver. With sulfated insulin, the amount was $31 \%$ greater $(63 \pm 2 \mathrm{mU} / \mathrm{min})$. The amounts of sulfated insulin leaving the liver exceeded those of insulin during the infusion of both 1 and $2 \mathrm{mU} / \mathrm{kg}$ per min of each hormone, by $88 \%$ and $80 \%$, respectively.

Hepatic extraction and metabolic clearance rates. During the control periods, the fractional hepatic extraction of insulin was similar in both groups (44 $\pm 4 \%$ and $49 \pm 8 \%$ ) (Fig. $4 \mathrm{~A}$ and $B)$. The infusion of 1 or $2 \mathrm{mU} / \mathrm{kg}$ per min of insulin had no effect on this value. In contrast, infusion of sulfated insulin was associated with a significant reduction of the fractional hepatic extraction to $15 \pm 2 \%$. The metabolic clearance rate of insulin was $34 \pm 1 \mathrm{ml} / \mathrm{kg}$ per min and was not different between the two periods of infusion. In comparison, the metabolic clearance rate of sulfated insulin was significantly less $(16 \pm 1 \mathrm{ml} / \mathrm{kg}$ per $\mathrm{min})$.

Plasma glucagon and glucagon balance across the liver. Basal portal vein glucagon concentrations were similar in both groups of dogs $(240 \pm 57 \mathrm{pg} / \mathrm{ml}$ and $161 \pm 35 \mathrm{pg} / \mathrm{ml})$ (Fig. $5 A$ and $B$ ). The initial increase in portal vein glucagon was more rapid after sulfated insulin than after insulin. At $30 \mathrm{~min}$ after the initiation of the infusion, the glucagon level increased from basal by $270 \pm 50 \%$ after sulfated insulin as compared with $103 \pm 20 \%$ after insulin. At the end of the infusion periods, glucagon concentra-
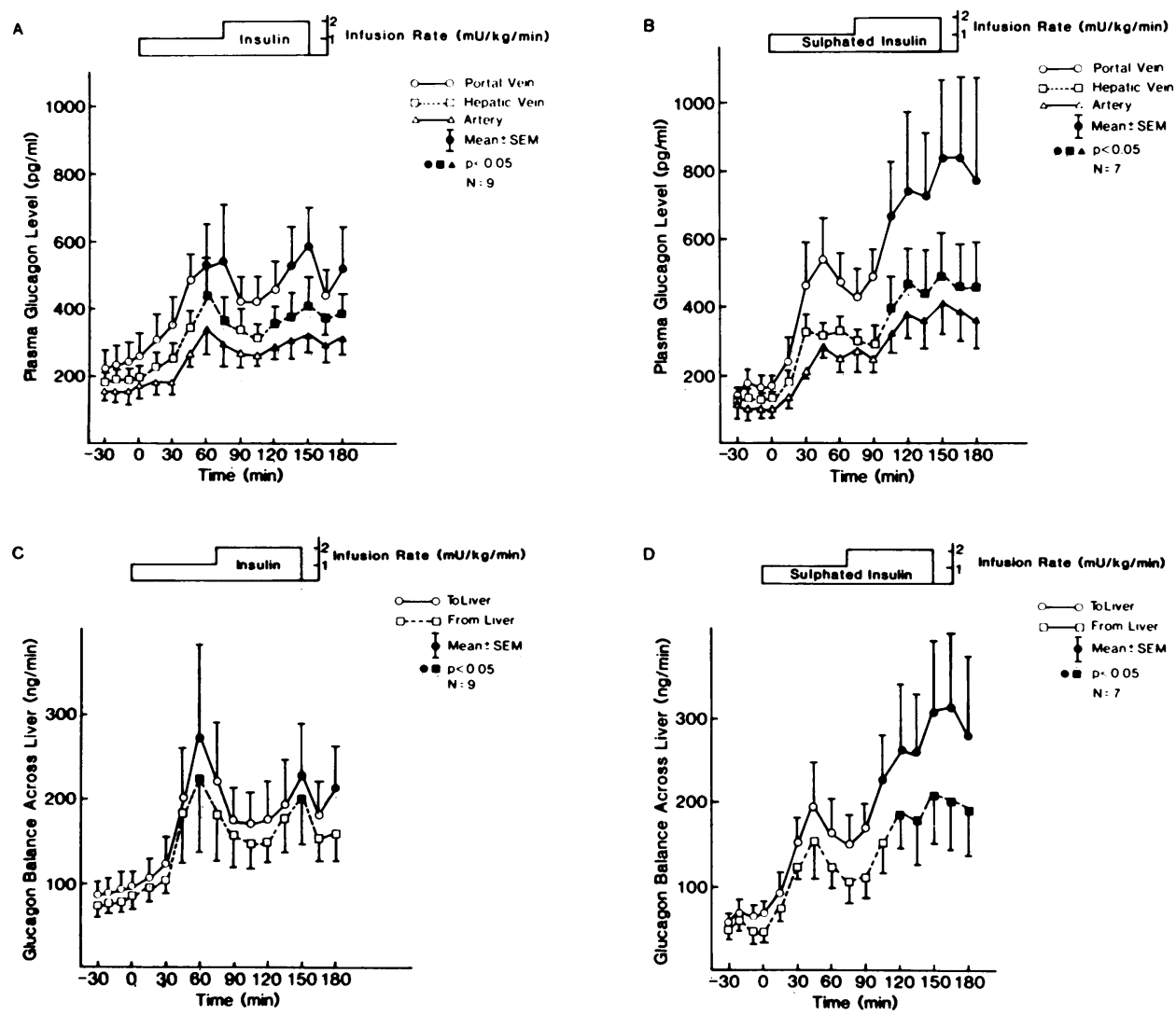

Figure 5. Plasma glucagon concentrations of portal vein (0), hepatic vein $(\square)$, and artery $(\Delta)$, after the infusion at 1 and $2 \mathrm{mU} /$ $\mathrm{kg}$ per min of insulin $(A)$ and sulfated insulin $(B)$. The amounts of glucagon delivered to $(O)$, and from (ㅁ) the liver after insulin $(C)$ and sulfated insulin $(D)$. Closed symbols are as in Fig. 3. 
tions were $589 \pm 111 \mathrm{pg} / \mathrm{ml}$ after insulin as compared with $841 \pm 233 \mathrm{pg} / \mathrm{ml}$ after sulfated insulin. There were parallel increases in the hepatic vein and arterial levels.

The fractional hepatic extraction of glucagon during the control period was $11 \pm 4 \%$ and $13 \pm 6 \%$ in the two groups and did not change significantly throughout the experiment. After the infusion of $1 \mathrm{mU} / \mathrm{kg}$ per min insulin or sulfated insulin, the amounts of glucagon to and from the liver significantly increased above basal (Fig. $5 C$ and $D$ ). However, since the basal amounts to the liver were less in the sulfated insulin group, the increment percent and increase in this group was greater. This difference in glucagon increment was more pronounced during the second period of sulfated insulin infusion. The total glucagon increment (area above the extended basal values) was $27.3 \pm 7.3 \mu \mathrm{g} / 3 \mathrm{~h}$ after sulfated insulin $(235 \pm 58 \%$ increase $)$ and $17.2 \pm 5.3 \mu \mathrm{g} / 3 \mathrm{~h}$ after insulin $(119 \pm 27 \%$ increase, $P<0.05)$.

Glucose and glucose turnover (Protocol III). As compared with insulin and sulfated insulin infused at 1 and $2 \mathrm{mU} / \mathrm{kg}$ per $\mathrm{min}$ (Fig. 2), $3 \mathrm{mU} / \mathrm{kg}$ per min insulin caused greater hypoglycemia as measured by the area under the extended basal level (Fig. $6 \mathrm{~A}$ ). Although the nadir levels $(41-45 \mathrm{mg} / 100 \mathrm{ml})$ were similar to those after 1 and $2 \mathrm{mU} / \mathrm{kg}$ per min of insulin and sulfated insulin, they occurred significantly earlier. In contrast to the effects with the lower dose insulin infusion ( 1 and $2 \mathrm{mU} /$ $\mathrm{kg}$ per $\mathrm{min}$ ), glucose appearance was not suppressed below basal at any time and after $135 \mathrm{~min}$, it increased significantly above basal values (Fig. $6 \mathrm{~B}$ ). Glucose disappearance significantly increased above basal by $30 \mathrm{~min}$ and remained elevated throughout the experiment (Fig. $6 \mathrm{C}$ ). The increased glucose disappearance was significantly greater than that achieved with 1 and $2 \mathrm{mU} /$ $\mathrm{kg}$ per min of insulin and comparable to that after 1 and $2 \mathrm{mU} /$ $\mathrm{kg}$ per min of sulfated insulin (Fig. $2 C$ ). Glucose clearance significantly increased above basal by $30 \mathrm{~min}$ (Fig. $6 \mathrm{D}$ ). The total increment above basal values was $881 \pm 116 \mathrm{ml} / \mathrm{kg}$ per 150 min $(123 \pm 12 \%)$ and significantly greater than after 1 and $2 \mathrm{mU} /$ $\mathrm{kg}$ per min of insulin (Fíg. $2 \mathrm{D}$ ).

Insulin and glucagon levels (protocol III). The basal portal vein insulin $(28 \pm 9 \mu \mathrm{U} / \mathrm{ml})$ was similar to the other experiments (Fig. $7 \mathrm{~A}$ ). The infusion of insulin at $3 \mathrm{mU} / \mathrm{kg}$ per min increased portal vein insulin to an average of $169 \pm 3 \mu \mathrm{U} / \mathrm{ml}$ and arterial insulin to $83 \pm 3 \mu \mathrm{U} / \mathrm{ml}$, while its metabolic clearance rate of $36 \pm 1 \mathrm{ml} / \mathrm{kg}$ per min was very similar to that observed after 1 or $2 \mathrm{mU} / \mathrm{kg}$ per min of insulin. Glucagon levels after the administration of $3 \mathrm{mU} / \mathrm{kg}$ per min increased significantly above basal by $45 \mathrm{~min}$ and reached a peak value of $1,118 \mathrm{pg} / \mathrm{ml}$ in the portal vein at $45 \mathrm{~min}$ (Fig. $7 \mathrm{~B}$ ). The increment above the extended basal levels of glucagon $(247 \pm 94 \%)$ was very similar to that observed after 1 and $2 \mathrm{mU} / \mathrm{kg}$ per $\mathrm{min}$ of sulfated insulin (Fig. $5 \mathrm{~B}$ ) and greater than after 1 and $2 \mathrm{mU} / \mathrm{kg}$ per min of insulin (Fig. $5 A$; see also Table I).

Glucose levels and glucose turnover (protocol IV). The infusion of sulfated insulin at 0.5 and $1 \mathrm{mU} / \mathrm{kg}$ per min caused a smaller decrease in glucose levels compared with the larger amounts of insulin or sulfated insulin (Fig. 8 and Fig. $2 \mathrm{~A}$ ). The basal plasma glucose was $79 \pm 2 \mathrm{mg} / 100 \mathrm{ml}$ and the nadir level after sulfated insulin was $47 \mathrm{mg} / 100 \mathrm{ml}$ at $75 \mathrm{~min}$ (Fig. $8 \mathrm{~A}$ ). The absolute decrement was $3,672 \pm 385 \mathrm{mg} / \mathrm{dl}$ per $3 \mathrm{~h}$ or $26 \pm 2 \%$ below the extended basal value (Table I). Glucose appearance did not change during either infusion period but significantly increased just after the termination of the infusion (Fig. $8 \mathrm{~B}$ ). Glucose disappearance modestly increased above basal values (Fig. $8 C$ ). However, this increment was significantly less than with 1 and $2 \mathrm{mU} / \mathrm{kg}$ per min infusion of this hormone or the 3 $\mathrm{mU} / \mathrm{kg}$ per min infusion of insulin and similar to the increment after the 1 and $2 \mathrm{mU} / \mathrm{kg}$ per min doses of insulin (Fig. $2 C$ and Fig. $6 C$ ). Glucose disappearance correlated quite well with the
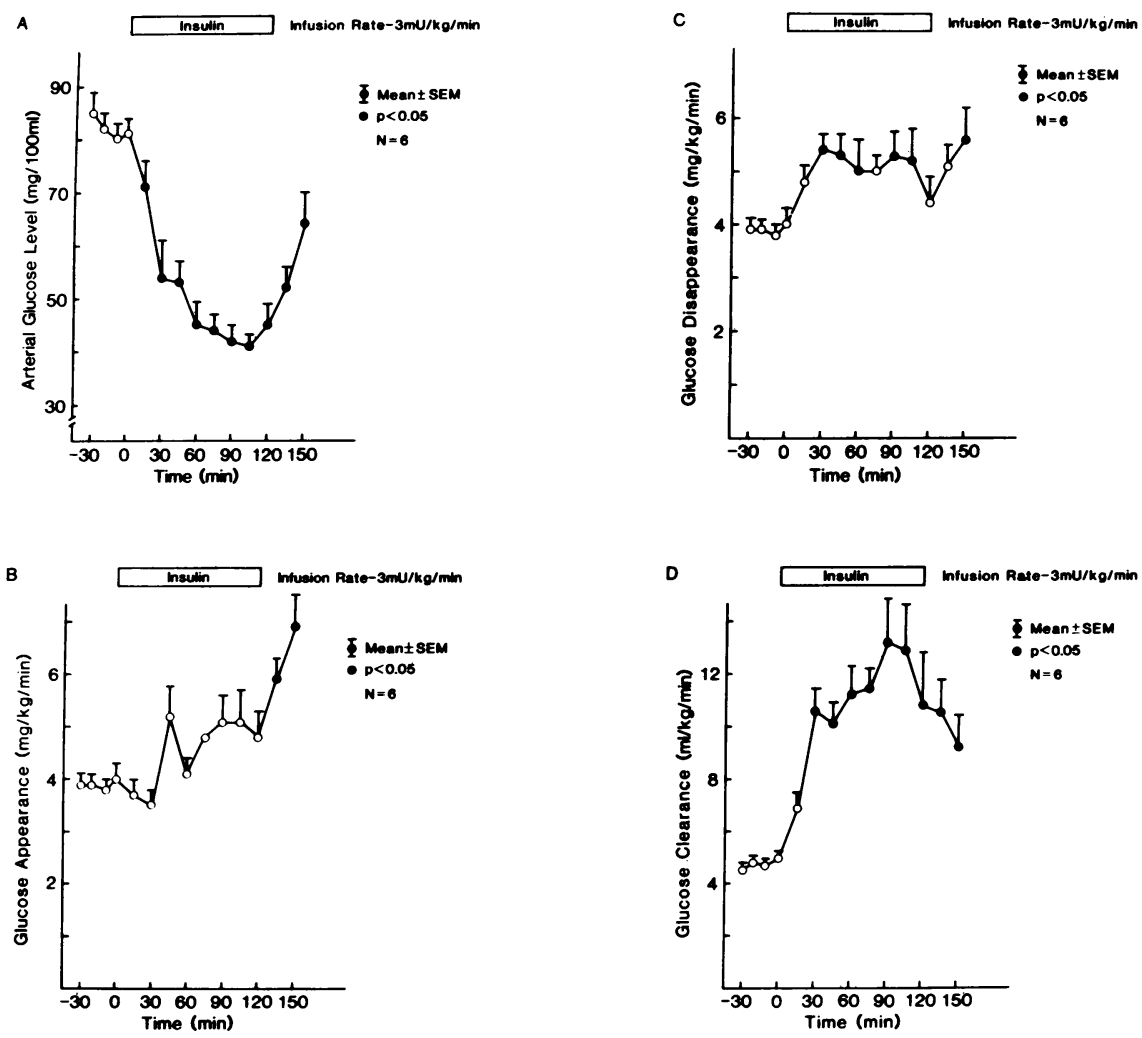

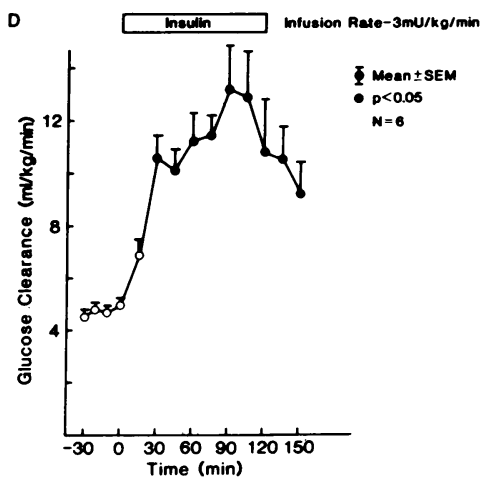

Figure 6. The effects of insulin infused into the portal vein at $3 \mathrm{mU} / \mathrm{kg}$ per min from 0 to 120 min on plasma glucose levels $(A)$, glucose appearance $(B)$, glucose disappearance $(C)$, and glucose clearance $(D)$. Closed symbols are as in Fig. 3. 


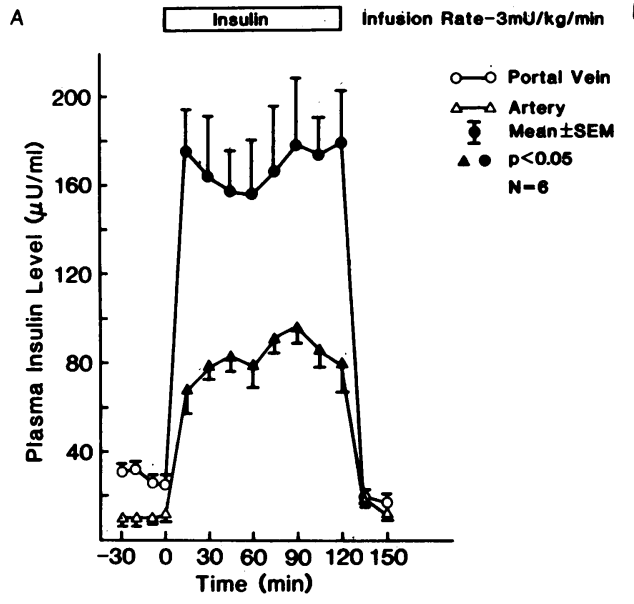

Figure 7. Plasma insulin concentrations $(A)$ of portal vein $(0)$, and artery $(\triangle)$, and glucagon levels $(B)$ of portal vein and artery after the infusion of insulin at $3 \mathrm{mU} / \mathrm{kg}$ per $\mathrm{min}$. Closed symbols are as in Fig. 3. peripheral insulin level. The glucose clearance increased significantly above basal at 120,135 , and $180 \mathrm{~min}$, reaching a peak value of $8.1 \pm 0.8 \mathrm{ml} / \mathrm{kg}$ per min at $135 \mathrm{~min}$ (Fig. $8 \mathrm{D}$ ). The total increment above the extended basal levels was $489 \pm 72 \mathrm{ml} / \mathrm{kg}$ per $3 \mathrm{~h}$ or a $69 \pm 12 \%$ increment (Table I) and almost identical to the values measured after the infusion of 1 and $2 \mathrm{mU} / \mathrm{kg}$ per min insulin (Fig. 2 D).

Insulin levels and glucagon response (protocol IV). Arterial insulin increased from the basal of $9 \pm 2 \mu \mathrm{U} / \mathrm{ml}$ to $34 \pm 1 \mu \mathrm{U} / \mathrm{ml}$ during the infusion of $0.5 \mathrm{mU} / \mathrm{kg}$ per min and to $59 \pm 1 \mu \mathrm{U} / \mathrm{ml}$ during the infusion of $1 \mathrm{mU} / \mathrm{kg}$ per min sulfated insulin. These arterial levels were similar to those observed after the infusion of 1 and $2 \mathrm{mU} / \mathrm{kg}$ per min of insulin (Fig. $3 \mathrm{~A}$ ) and approximately half of those observed after 1 and $2 \mathrm{mU} / \mathrm{kg}$ per min of sulfated insulin (Fig. $3 \mathrm{~B}$ ). Accordingly, the metabolic clearance rate of sulfated insulin was similar to that measured during the infusion of the larger doses, $16 \pm 1 \mathrm{ml} / \mathrm{kg}$ per min. Although the nadir glucose value was higher and delayed and the total hypoglycemic decrement after $0.5 \mathrm{mU} / \mathrm{kg}$ per min sulfated insulin were less than with the double doses of insulin $(26 \pm 2 \%$ vs. $31 \pm 2 \%$, respectively), the glucagon increment was similar, $129 \pm 43 \%$ over $3 \mathrm{~h}$ as compared with $119 \pm 27 \%$ after 1 and $2 \mathrm{mU} / \mathrm{kg}$ per min of insulin. This was in correlation with similar increments in glucose clearance in these two groups (Figs. $2 \mathrm{D}$ and $8 \mathrm{D}$ ).

Glucose levels and glucose turnover (protocol IV). Sulfated insulin infused at 0.25 and $0.5 \mathrm{mU} / \mathrm{kg}$ per min decreased plasma glucose from the basal of $80 \pm 4 \mathrm{mg} / \mathrm{dl}$ to a nadir of $59 \pm 7 \mathrm{mg} /$ dl at $135 \mathrm{~min}$ (Fig. $9 A$ ). The total hypoglycemic decrement as
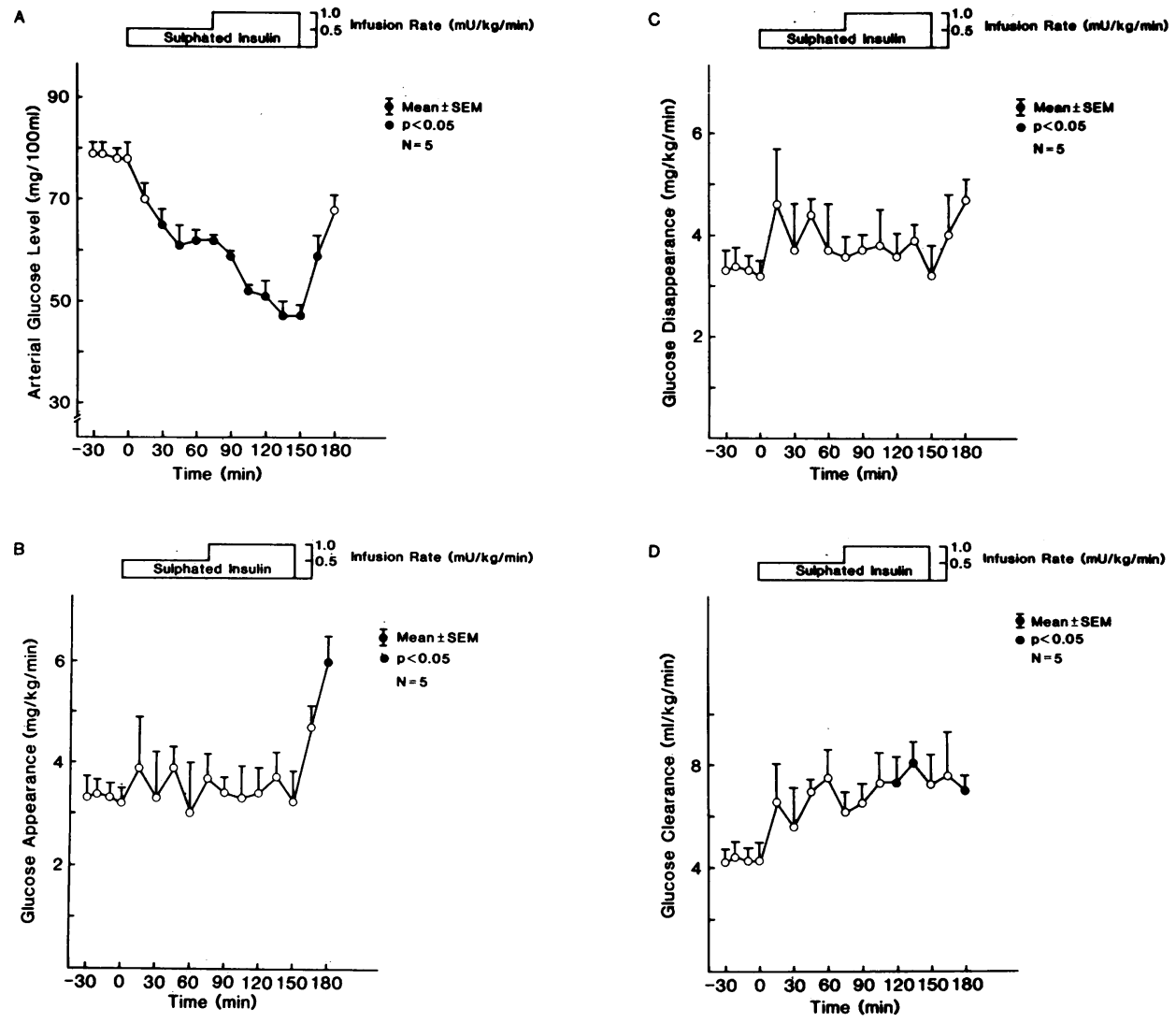

Figure 8 . The effects of sulfated insulin infused into the portal system at 0.5 and $1 \mathrm{mU} / \mathrm{kg}$ per $\min$ on plasma glucose levels $(A)$, glucose appearance $(B)$, glucose disappearance $(C)$, and glucose clearance $(D)$. Closed symbols are as in Fig. 3. 

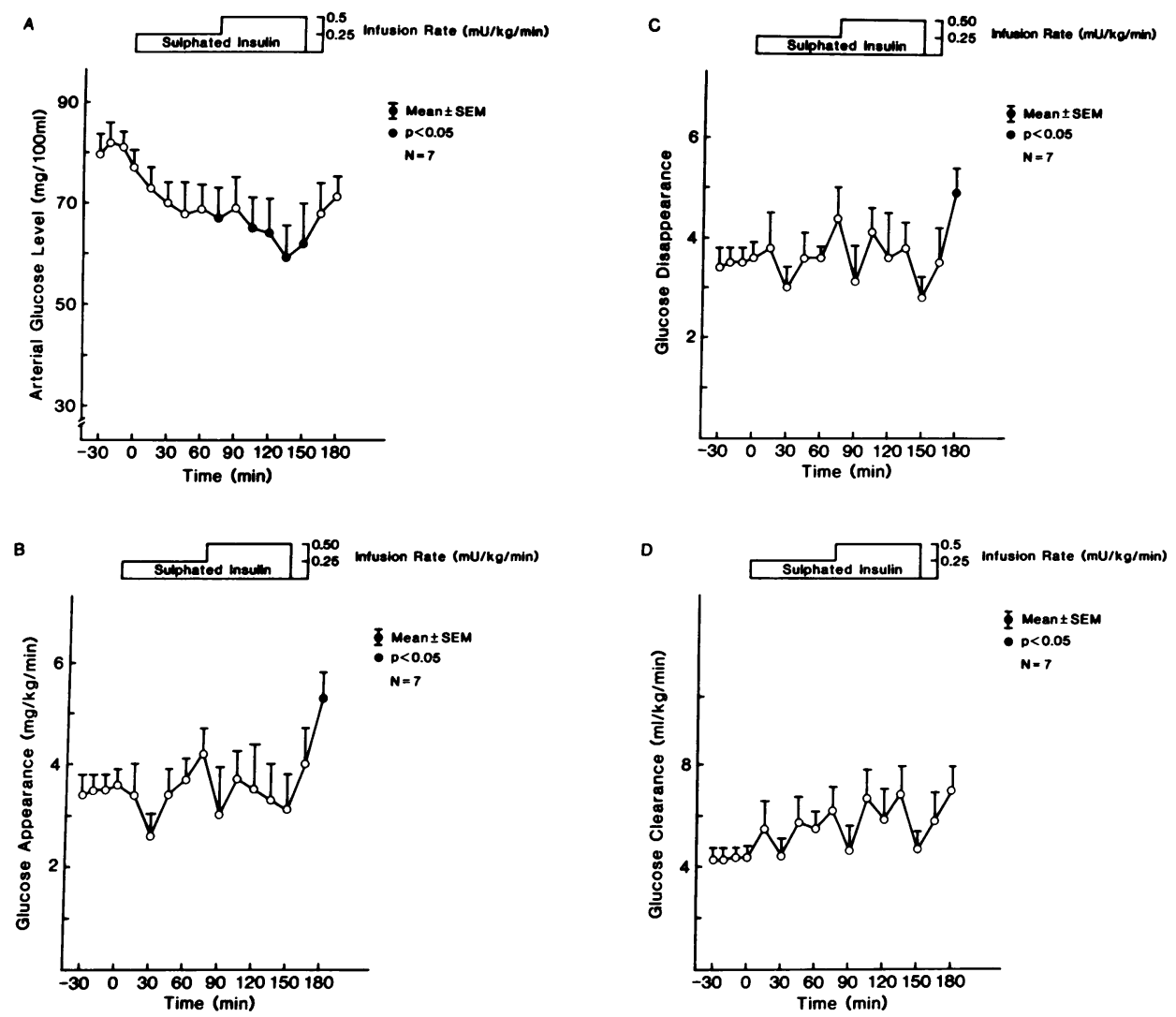

Figure 9. The effects of sulfated insulin infused into the portal system at 0.25 and $0.5 \mathrm{mU} / \mathrm{kg}$ per min on plasma glucose levels $(A)$, glucose appearance $(B)$, glucose disappearance $(C)$, and glucose clearance $(D)$. Closed symbols are as in Fig. 3.

determined by the area below the extended basal value was $2,250 \pm 440 \mathrm{mg} / \mathrm{dl}$ per $3 \mathrm{~h}$ or $16 \pm 4 \%$. Glucose appearance did not decrease significantly below basal at any time and was significantly above basal at $180 \mathrm{~min}$ (Fig. $9 \mathrm{~B}$ ). The glucose disappearance did not increase significantly above basal values (Fig. $9 \mathrm{C})$. Glucose clearance increased from the basal of $4.4 \pm 0.4 \mathrm{ml} /$ $\mathrm{kg}$ per min to a peak of $6.9 \pm 1.1 \mathrm{ml} / \mathrm{kg}$ per min at $135 \mathrm{~min}$ (Fig. $9 \mathrm{D}$ ). The total increment above the extended basal level over the 3 - $h$ period was $33 \pm 6 \%$ and was significantly less than in all the other experimental groups as shown in Table $I$.

Glucose utilization and production during euglycemic clamp (protocol $\mathrm{V}$ ). The basal glucose level was clamped during the infusion of 1 and $2 \mathrm{mU} / \mathrm{kg}$ per min of insulin or sulfated insulin (Fig. $10 \mathrm{~A}$ ). The amounts of exogenous glucose required to maintain euglycemia were significantly greater during the infusion of sulfated insulin as compared with insulin. The average infusion rates of glucose over the period of the hormone infusion were $6.1 \pm 0.5$ and $4.2 \pm 0.4 \mathrm{mg} / \mathrm{kg}$ per min, respectively. Endogenous glucose production was significantly and equally suppressed by both insulin and sulfated insulin (Fig. $10 \mathrm{~B}$ ). At the end of the infusion period $(150 \mathrm{~min})$ the residual endogenous glucose production was not significantly different from $0(0.4 \pm 0.4$ $\mathrm{mg} / \mathrm{kg}$ per min after insulin and $-0.4 \pm 0.8 \mathrm{mg} / \mathrm{kg}$ per min after sulfated insulin). At no time point was there any significant difference in the residual endogenous glucose production between the two groups.

Binding to liver plasma membranes. The binding of sulfated insulin to liver plasma membranes was examined both on a molar and biologic potency basis (Fig. 11). The displacement of ${ }^{125} \mathrm{I}$-insulin by sulfated insulin was only $25 \%$ of that by insulin when expressed on a molar basis (Fig. $11 \mathrm{~A}$ ). However, this significantly lower binding affinity (expected because of the negative charge added to the insulin molecule by the sulphation-sulfonation process) was proportional to the loss in biologic potency. Thus, when binding was based on the same concentrations in terms of biologic potency, the two insulins behaved identically (Fig. $11 B$ ).

\section{Discussion}

Infusion into the portal vein of insulin and sulfated insulin, which had markedly different fractional hepatic extractions and metabolic clearance rates, provided significantly different peripheral and portal insulin concentrations and thus permitted an assessment of this differential distribution of insulin on the hepatic and peripheral contribution to hypoglycemia. Despite similar hypoglycemia induced by both insulin and sulfated insulin, the results indicated a significant difference in the role of peripheral and hepatic glucose metabolism and that glucagon counterregulation is not simply a reflection of the extent of hypoglycemia. Studies using the euglycemic clamp or a larger amount of insulin ( $3 \mathrm{mU} / \mathrm{kg}$ per min) showed that both insulin and sulfated insulin suppressed hepatic glucose production equivalently, but such an effect can be masked by counter-regulatory factors during hypoglycemia.

The metabolic clearance rate (MCR) ${ }^{1}$ of insulin was significantly greater than that of sulfated insulin $(34 \pm 1 \mathrm{vs} .16 \pm 1 \mathrm{ml} /$ $\mathrm{kg}$ per min, respectively) and similar to that previously reported $(8,19,25)$. The reason for the difference between our value for sulfated insulin and that reported by Nomura et al. $(5.75 \mathrm{ml} / \mathrm{kg}$ per $\min$ ) (4) is not clear but could reflect the different experimental conditions. In their study (4), sulfated insulin was infused

1. Abbreviations used in this paper: MCR, metabolic clearance rate. 


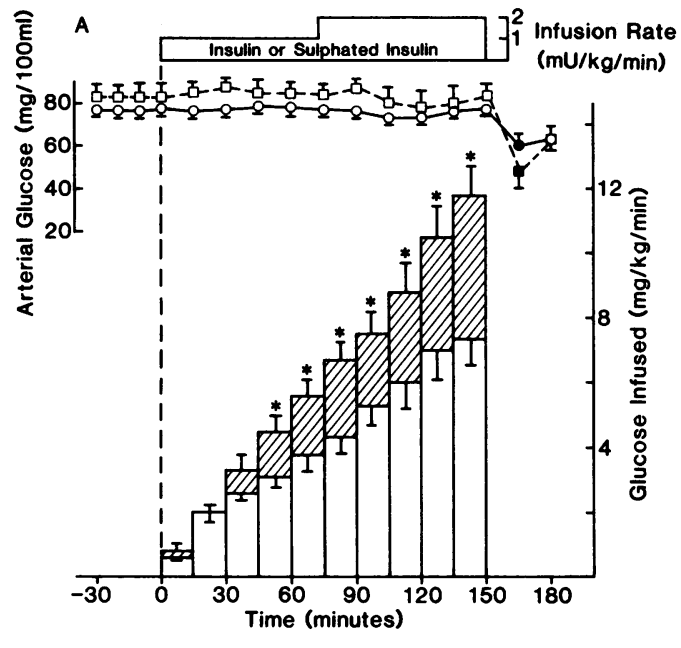

B

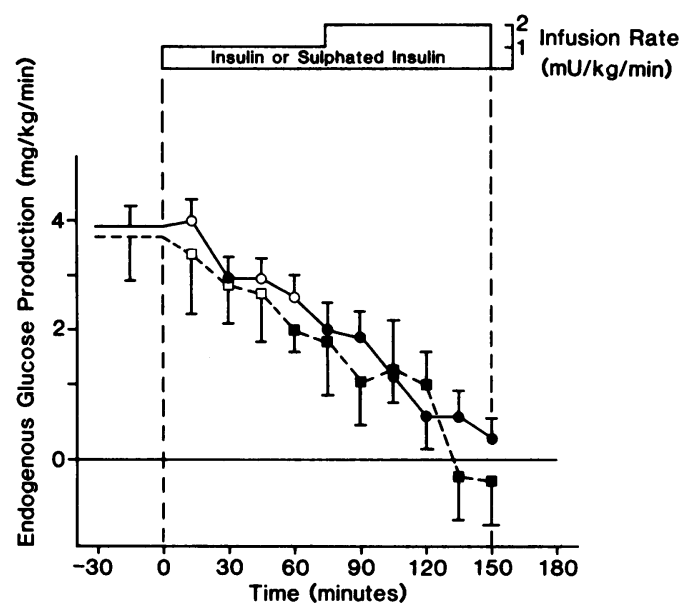

Figure 10. The effects of insulin (o; $n=7)$ and sulfated insulin ( $\square ; n$ $=6$ ) on glucose metabolism during a euglycemic clamp. $(A)$ glucose levels during the infusion of insulin ( $O$ ) and sulfated insulin ( $\square$ ) and the amounts of exogenous glucose infused. Open bars, insulin; hatched bars, sulfated insulin. $(B)$ endogenous glucose production after the infusion of insulin (O) and sulfated insulin ( $\square$ ) during the euglycemic clamp. $\$$, mean \pm SEM; $\bullet$ and $\curvearrowleft, P<0.05$ vs. basal; $*, P<0.05$ vs. insulin.

intraportally at an average dose of $0.2 \mathrm{mU} / \mathrm{kg}$ per min in three dogs for $140 \mathrm{~d}$ and the hormone level was measured in peripheral venous blood (11). Although the amount of sulfated insulin that they used was lower than our lowest dose, we did not find any significant difference in MCR with doses between 0.25 and 2 $\mathrm{mU} / \mathrm{kg}$ per min.

The fractional hepatic extraction of sulfated insulin, $15 \pm 2 \%$, was significantly less than that of insulin, $42 \pm 1 \%$. The latter value confirms previous results $(8,19,25)$. The significantly lower MCR and hepatic extraction of sulfated insulin caused the greater concentrations in all three blood vessels of the modified insulin as compared with insulin when infused at 1 and $2 \mathrm{mU} / \mathrm{kg}$ per min. However, their relative distribution between peripheral and portal blood compartments was significantly greater after sulfated insulin than after insulin. While the amounts of sulfated insulin leaving the liver (hepatic vein concentration) exceeded those of insulin by approximately twofold, the difference in the amounts reaching the liver was $\sim 30 \%$ (portal vein and arterial levels).
This different relative distribution (arterial/portal ratio was 0.67 after sulfated insulin as compared with 0.45 after insulin) was the direct result of the lower hepatic extraction and MCR of the sulfated insulin. At any given moment, the concentration in the portal vein is the result of the newly infused hormone (the same amounts for both insulins) and the amounts recirculating into the portal system. The latter were approximately twofold greater after sulfated insulin than after insulin. On the other hand, the hepatic vein and consequently the arterial insulin levels are modulated by the hepatic extraction of both the newly infused and recirculating hormones. The different ratio between the peripheral and portal blood compartments remained constant since the hepatic fractional extraction and the MCR of both insulins did not change with the various amounts infused.

The effects of insulin on glucose levels, glucose appearance, disappearance, and clearance confirm previous reports (16, 2528 ). Thus, insulin-induced hypoglycemia reflects both suppression of hepatic glucose production and increased glucose utilization. The initial net suppression of hepatic glucose production by insulin does not persist despite the continuing presence of elevated insulin levels, since the ensuing hypoglycemia causes counterregulatory stimulation such that hepatic glucose production exceeds the basal value. Sulfated insulin and insulin infused at 1 and $2 \mathrm{mU} / \mathrm{kg}$ per min caused the same hypoglycemia $(31 \pm 2 \%$ decrement). However, the hypoglycemia after sulfated insulin appeared to reflect almost exclusively increased peripheral glucose utilization, which was significantly greater than that achieved by insulin, and no net suppression of hepatic glucose production was observed. However, the studies using the euglycemic clamp clearly showed that sulfated insulin was equally as effective as insulin in suppressing hepatic glucose production. Thus, the apparent lack of suppression of hepatic glucose production when sulfated insulin was infused and hypoglycemia was induced reflects the masking effect of counterregulation. If such counterregulatory stimulation of glucose production were not greater with sulfated insulin, the hypoglycemia achieved would have been greater than after equivalent amounts of insulin, since the effect of the former on glucose utilization was significantly greater. Such apparent masking of the suppression of hepatic glucose production is supported by the results obtained with larger amounts of insulin ( $3 \mathrm{mU} / \mathrm{kg}$ per $\mathrm{min})$, since net suppression of hepatic glucose production was also not detected. However, it is possible that an earlier, transient suppression of hepatic glucose production was present but was not observed because the first time point examined was at $15 \mathrm{~min}$. The masking of the suppressive effect of the larger dose of insulin on glucose production was associated with significantly earlier and greater increments in glucagon levels than after 1 and $2 \mathrm{mU} / \mathrm{kg}$ per min of insulin. This result confirms the earlier observations by Madison et al. (29), who measured the effects of different doses of insulin on hepatic glucose production in dogs with portacaval shunts. Although our results were qualitatively similar to their results, we observed the apparent masking of the insulin effect on hepatic glucose production with considerably less hormone. The reason for this difference is not clear but may reflect the different animal models employed. The larger dose of insulin that they required to demonstrate masked suppression of glucose production might reflect the fact that glucagon (which was not measured) was diverted from the liver by the portacaval shunt. Although not the only counterregulatory hormone (3-7), glucagon plays a predominant role in overcoming acute insulininduced hypoglycemia $(2,30-32)$. 

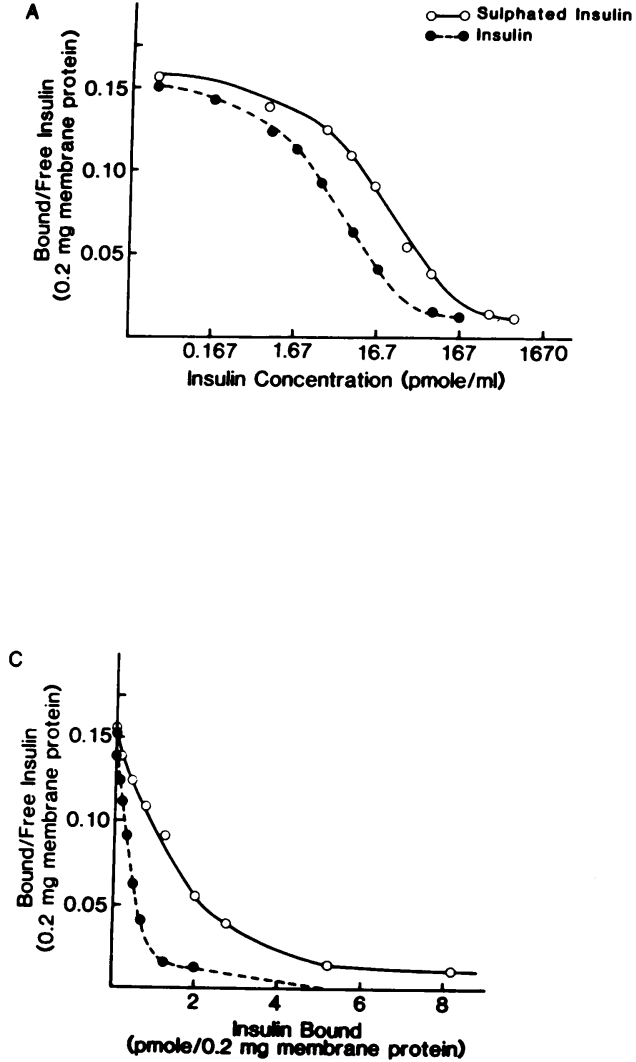

The increasing effect of insulin on glucose clearance without a commensurate change in hepatic glucose production can be explained by the significantly earlier saturation of the effect of insulin on glucose production as compared with its effect on glucose utilization, as has been demonstrated by Rizza et al. (1) using the glucose clamp technique combined with infusion of $\left[{ }^{3} \mathrm{H}\right]$ glucose. They reported that the effect of insulin on glucose production is more sensitive than that on glucose utilization. A peripheral insulin concentration of $60 \mu \mathrm{U} / \mathrm{ml}$ was saturating for suppression of glucose production as compared with 200-750 $\mu \mathrm{U} / \mathrm{ml}$ for the effect on glucose utilization. Thus, once saturating levels of insulin or sulfated insulin for the hepatic effect have been achieved, any additional increase in the peripheral concentrations of insulin would increase glucose utilization and cause greater counterregulatory effect on glucose production, which would mask the hepatic effects of insulin or its analogue.

The equivalent effect of insulin and sulfated insulin on the suppression of hepatic glucose production is consistent with their similar binding affinity to liver plasma membranes when the results are corrected for biologic potency $(11,33)$. The binding affinity we have observed for sulfated insulin is very similar to that which Zeuzem et al. (34) also reported for liver plasma membranes. Despite equivalent binding affinities of the two insulins, there was a marked discrepancy in their hepatic extraction. Hepatic extraction only defines the amount of insulin removed by that organ but does not provide information concerning its fate or necessarily its biologic effect. Although binding to the receptor is the first step in insulin internalization (35) and degradation $(36,37)$, insulin may be degraded without exerting biologic effects (38-40). Krupp and Livingston (41) found three different membrane components, two of which bound insulin

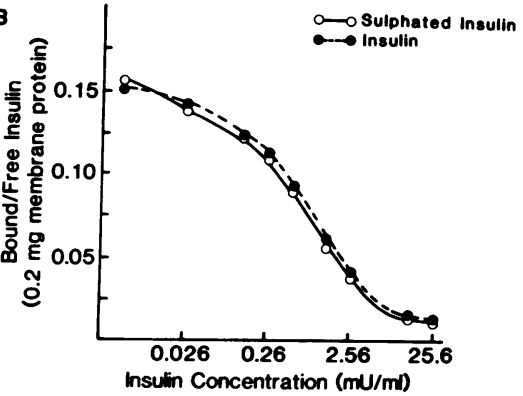

Figure 11. The binding of insulin $(\bullet)$ and sulfated insulin (o) to rat liver membranes as determined by displacement of ${ }^{125}$ I-insulin. The experimental conditions are described in Methods. The bound/free ratio of ${ }^{125}$ I-insulin is plotted as a function of insulin concentration on molar basis $(A)$ and in terms of biologic potency $(B)$. Bottom, Scatchard analysis for insulin and sulfated insulin. The bound/free ratio of ${ }^{125} \mathrm{I}$-insulin is plotted as a function of the bound insulin or sulfated insulin expressed in terms of moles $(C)$ or biologic potency $(D)$. Both axes are normalized to $0.2 \mathrm{mg}$ membrane protein. The results are the mean of triplicate determinations in three experiments on three different preparations of liver membranes. The SEM ranged from 2 to $8 \%$ at all concentrations. but did not degrade it and one which bound and degraded the hormone. Thus, the differential changes in sulfated insulin degradation as compared with its binding affinity to hepatic receptors may be the explanation for the dissociation between its binding affinity and hepatic extraction we observed. In addition, it was reported that internalization and thus intracellular degradation are not required for some of the biologic effects of insulin in the liver (42) and adipose tissue (43). An effect of sulfated insulin on suppression of hepatic glucose production during hypoglycemia is also documented in the present study by the rapid increase in glucose appearance when infusion of sulfated insulin was stopped. At this time, sulfated insulin levels decreased rapidly while glucagon concentrations were high and decreased more gradually. The same responses of glucose appearance occurred after the termination of insulin infusion. Our results indicate that the peripheral and hepatic effects of sulfated insulin were similar to insulin and proportional to its concentrations in terms of biologic potency. Thus, when sulfated insulin was infused at 0.5 and $1.0 \mathrm{mU} / \mathrm{kg}$ per min, its peripheral concentrations were similar to those achieved after 1 and $2 \mathrm{mU} / \mathrm{kg}$ per min of insulin, with equivalent effects on glucose clearance. This is compatible with the relative change in binding affinity of sulfated insulin in human and rat adipocytes (4-4.5 times less than insulin) as reported by Zeuzem et al (34).

Therefore, the absence of suppression of glucose production with the smaller doses of sulfated insulin cannot be accounted for by differential changes in the hepatic and peripheral binding affinities, and stems from the fact that a different distribution of the hormones occurs between the portal and peripheral blood compartments associated with a greater increment in glucagon levels after sulfated insulin despite the same hypoglycemia. This 
result strongly suggests that the magnitude and onset of counterregulation to insulin-induced hypoglycemia is not simply related to glucose levels or total hypoglycemic decrement but is also related to the peripheral level and/or effect of insulin. Thus, infusion of sulfated insulin at 0.5 and $1 \mathrm{mU} / \mathrm{kg}$ per min caused the same arterial concentrations and similar effects on glucose disappearance and clearance as did twice as much insulin ( 1 and $2 \mathrm{mU} / \mathrm{kg}$ per $\mathrm{min}$ ), and the counterregulatory onset of glucagon was also similar despite less hypoglycemia. On the other hand, infusion of 0.5 and $1 \mathrm{mU} / \mathrm{kg}$ per min of sulfated insulin is associated with significantly lower concentrations in the portal vein compared with infusion of 1 and $2 \mathrm{mU} / \mathrm{kg}$ per min of insulin because of its different distribution between the portal and arterial blood compartments. Therefore, the absence of net suppression of glucose production after the smaller doses of sulfated insulin could be due to the different response of glucagon in the presence of less sulfated insulin presented to the liver. It has been repeatedly reported in the past that insulin/glucagon molar ratio can modify hepatic glucose production (44, 45; and Chap, Z., T. Ishida, J. Chou, R. Lewis, C. Hartley, M. Entman, and J. B. Field, manuscript submitted for publication). The present study confirms this concept and provides evidence that the effect on glucose production at any moment during insulin-induced hypoglycemia is determined by the antagonistic effects of insulin and glucagon (or all counterregulatory hormones) delivered to the liver.

While hypoglycemia always is associated with counterregulation, it is not always clear whether it is the absolute decrease in glucose level below basal (30) or the rate of fall (2) that initiates counterregulation after insulin-induced hypoglycemia. DeFronzo et al. (30) have demonstrated that the rate of fall in glucose level, per se, does not stimulate secretion of any of the counterregulatory hormones. However, this was demonstrated with falling levels from hyperglycemia. By using the modified insulin, we showed that hypoglycemic levels (absolute, rate of fall, or total hypoglycemic decrement) do not solely determine the rate of glucagon response. This corresponds better with the peripheral concentrations and effect of insulin on glucose clearance, which is a measure determined by the glucose level and rate of glucose utilization (see Table I).

Obviously, hypoglycemia is essential for the stimulation of glucagon secretion, since maintenance of euglycemia despite increased removal of glucose associated with hyperinsulinemia was reported not to increase glucagon secretion (33). This was confirmed in the euglycemic clamp studies (data not shown). Furthermore, hyperglycemia in the face of hyperinsulinemia and augmented glucose clearance suppresses glucagon secretion (46, 47). The mechanism by which insulin causes an increase in glucagon secretion beyond its effect on lowering plasma glucose levels remains unclear. Recently, Gorus et al. (48) have reported that insulin does not have any effect on glucose uptake and glucose oxidation in purified pancreatic A-cells. Unger (49) suggested that the beta cell is the principal glucose sensor of the islet, and decrements in blood glucose stimulate the alpha cell by suppression of insulin secretion. This view of interaction between the pancreatic $B$ and A cells in the regulation of glucagon secretion is further supported by recent reports $(50,51)$. Since suppression of endogenous insulin secretion by exogenous insulin is proportional to hyperinsulinemia, it is possible that sulfated insulin had a greater inhibitory effect on endogenous insulin secretion due to its greater arterial concentrations. However, controversial conclusions regarding the role of peripheral and intra-islet insulin levels in the regulation of glucagon secretion during hypoglycemia have also been reported (52). It is also possible that the relatively small but significant increment in glucagon response after sulfated insulin is related by an indirect mechanism to its greater peripheral effect on glucose utilization. Mezey et al. (53) reported that insulin stimulates the secretion of adrenocorticotropin by a mechanism in which catecholamines of peripheral origin act directly on the anterior pituitary. Furthermore, catecholamines within the pancreas itself might mediate glucagon response to glucopenia (54). The significant increments of other counterregulatory hormones (catecholamines, glucocorticosteroids, and growth hormone) during insulin-induced hypoglycemia are well known phenomena. These also could have contributed directly to the significantly greater compensatory increase in glucose production after sulfated insulin. The effects of glucagon, catecholamines, and cortisol on hepatic glucose production, when infused together, are synergistic (55). Thus, even relatively small alterations in the response of these hormones to insulin infusion may result in an amplified effect on hepatic glucose production.

The implication of the present data is that insulin administered by different routes (i.e., intraportal vs. peripheral) cause decrease in glucose levels by different mechanisms, in which the peripheral tissues and the liver have different contributions, even if the glucose level is suppressed similarily. This stems from the fact that absolutely different distribution of insulin occurs between the portal and arterial blood compartments after the different routes of administration.

\section{Acknowledgments}

The authors wish to acknowledge the staff of the Cardiovascular Science Division of the Department of Medicine for their superb help in the execution of these surgeries, and Lucy Whitlock, Hormone Radioimmunoassay Core of the Diabetes and Endocrinology Research Center, for her expert execution of the hormone assays. We would also like to thank Barbara Sims, Mary Ann Farabee, and Shelley Dearing for their outstanding assistance in the preparation of this manuscript.

This work was supported by U. S. Public Health Service grants AM 25253 and AM 27685.

\section{References}

1. Rizza, R. A., L. J. Mandarino, and J. E. Gerich. 1981. Doseresponse characteristics for the effects of insulin on production and utilization of glucose in man. Am. J. Physiol. 240:E630-E639.

2. Gerich, J. E., V. Schneider, S. E. Dippe, M. Langlois, C. Noacco, J. Karam, and P. H. Forsham. 1974. Characterization of the glucagon response to hypoglycemia in man. J. Clin. Endocrinol. Metab. 38:7782.

3. Roth, J., S. M. Glick, R. S. Yalow, and S. A. Berson. 1963. Hypoglycemia: a potent stimulus to secretion of growth hormone. Science (Wash. DC). 140:987-988.

4. Levine, R. 1963. Analysis of the action of the hormonal antagonists of insulin. Diabetes. 13:362-365.

5. Greenwood, F. C., J. Landon, and T. C. B. Stamp. 1966. The plasma sugar, free fatty acid, cortisol, and growth hormone response to insulin. I. In control subjects. J. Clin. Invest. 45:429-436.

6. Lilavivathana, U., R. G. Brodows, P. D. Woolf, and R. G. Campbell. 1979. Counterregulatory hormonal responses in rapid glucose lowering in diabetic man. Diabetes. 28:873-877. 
7. Christensen, N. J. 1974. Plasma norepinephrine and epinephrine in untreated diabetics during fasting and after insulin administration. Diabetes. 23:1-8.

8. Ishida, T., J. Chou, R. M. Lewis, C. J. Hartley, M. Entman, and J. B. Field. 1983. Comparison of hepatic extraction of insulin and glucagon in conscious and anesthetized dogs. Endocrinology. 112:10981109.

9. Somogyi, M. 1945. Determination of blood sugars. J. Biol. Chem. $160: 68-73$

10. Herbert, V., K. S. Lau, C. W. Gottlieb, and S. J. Bleicher. 1965. Coated charcoal immunoassay of insulin. J. Clin. Endocrinol. Metab. 25:1375-1379.

11. Nomura, M., B. Zinman, A. Bahoric, E. B. Marliss, and A. M. Albisser. 1983. Intravenous infusion of sulfated insulin normalize plasma glucose levels in pancreatectomized dogs. Diabetes. 32:788-792.

12. Faloona, G. R., and R. H. Unger. 1972. Glucagon. In Methods of Hormone Radioimmunoassay. B. M. Jaffe and H. R. Berman, editors. Academic Press, New York. 317-330.

13. Hartley, C. J., and J. S. Cole. 1974. An ultrasonic pulsed Doppler system for measuring blood flow in small vessels. J. Appl. Physiol. 37: 626-629.

14. Hartley, C. J., H. G. Hanley, R. M. Lewis, and J. S. Cole. 1978. Synchronized pulsed Doppler blood flow and ultrasonic dimension measurement in conscious dogs. Ultrasound Med. Biol. 4:99-110.

15. Steele, R. 1959. Influence of glucose loading and of injected insulin on hepatic glucose output. Ann. NY Acad. Sci. 82:420-430.

16. DeBodo, R., R. Steele, N. Altszuler, A. Dunn, and J. Bishop. 1963. On the hormonal regulation of carbohydrate metabolism: studies with ${ }^{14} \mathrm{C}$-glucose. Recent Prog. Horm. Res. 19:445-488.

17. Cowan, J. S., and G. Hetenyi, Jr. 1971. Glucoregulatory responses in normal and diabetic dogs recorded by a new tracer method. Metabolism. 20:360-372.

18. Altszuler, N., A. Barkai, C. Bjerknes, B. Gottlieb, and R. Steele. 1975. Glucose turnover values in the dog obtained with various species of labeled glucose. Am. J. Physiol. 229:1662-1667.

19. Ishida, T., Z. Chap, J. Chou, R. M. Lewis, C. J. Hartley, M. L. Entman, and J. B. Field. 1984. Hepatic extraction of exogenous insulin in depancreatized conscious dogs. Am. J. Physiol. 246:E369-E379.

20. Neville, D. M., Jr. 1968. Isolation of an organ specific protein from surface membrane of rat liver. Biochem. Biophys. Acta. 154:540552.

21. Birnbaumer, L., T. L. Swartz, J. Abramovitz, P. W. Mintz, and R. Iyengar. 1980. Transient and steady state kinetics of the interaction of guanyl nucleotides with the adenylyl cyclase system from rat liver plasma membranes. J. Biol. Chem. 255:3542-3551.

22. Kahn, C. R., I. D. Goldfine, D. M. Neville, and P. DeMeyts. 1978. Alterations in insulin binding induced by changes in vivo in the levels of glucocorticoids and growth hormone. Endocrinology. 103:1054 1066.

23. Soll, A. H., and C. R. Kahn. 1975. Insulin binding to liver plasma membranes in the obese hyperglycemic (ob/ob) mouse. J. Biol. Chem. 250:4702-4707.

24. Lowry, O. H., N. J. Rosebrough, A. L. Farr, and R. J. Randall. 1951. Protein measurement with the Folin reagent. J. Biol. Chem. 193: 265-275.

25. Ishida, T., Z. Chap, J. Chou, R. M. Lewis, C. J. Hartley, M. L. Entman, and J. B. Field. 1984. Effects of portal and peripheral venous insulin on glucose production and utilization in depancreatized dogs. Diabetes. 33:984-990.

26. Hetenyi, C., Jr., G. A. Wrenshall, and C. H. Best. 1961. Rates of production, utilization, accumulation and apparent distribution space of glucose. Effects of insulin in dogs using a validated tracer method. Diabetes. 10:304-311.

27. Vranic, M., and G. A. Wrenshall. 1968. Matched rates of insulin infusion and secretion and concurrent tracer-determined rates of glucose appearance and disappearance in fasting dogs. Can. J. Physiol. Pharmacol. 46:383-390.
28. Tompkins, C. V., D. Brandenburg, R. H. Jones, and P. H. Sonksen. 1981. Mechanism of aetion of insulin and insulin analogues. Diabetologia. 20:94-101.

29. Madison, L. L., B. Combes, R. Adams, and W. Strickland. 1960. The physiological significance of the secretion of endogenous insulin into the portal circulation. III. Evidence for a direct immediate effect of insulin on the balance of glucose across the liver. J. Clin. Invest. 39:507522.

30. DeFronzo, R. A., R. Andres, T. A. Bledsoe, G. Boden, G. A. Faloona, and J. D. Tobin. 1977. A test of the hypothesis that the rate of fall in glucose concentration triggers counterregulatory hormonal responses in man. Diabetes. 26:445-452.

31. Clarke, W. L., J. V. Santiago, L. Thomas, E. Ben-Galin, M. W. Haymond, and P. E. Cryer. 1979. Adrenergic mechanisms in recovery from hypoglycemia in man: adrenergic blockade. Am. J. Physiol. 236: E147-E152.

32. Rizza, R. A., P. E. Cryer, and J. E. Gerich. 1979. Role of glucagon, catecholamines, and growth hormone in human glucose counterregulation. Effects of somatostatin and combined $\alpha$-and $\beta$-adrenergic blockade on plasma glucose recovery and glucose flux rates after insulin-induced hypoglycemia. J. Clin. Invest. 64:62-71.

33. Moloney, P. J., M. A. Aprile, and S. Wilson. 1964. Sulfated insulin for treatment of insulin-resistant diabetics. J. New Drugs. 4:258263.

34. Zeuzem, S., R. Taylor, L. Augius, A. M. Albisser, and K. G. M. M. Alberti. 1984. Differential binding of sulphated insulin to adipocytes and hepatocytes. Diabetologia. 27:184-188.

35. Gordon, P., J. L. Carpentier, P. Freychet, and L. Orci. 1980. Internalization of polypeptidé hormones mechanism, intracellular localization and significance. Diabetologia. 18:263-274.

36. Terris, S., and D. F. Steiner. 1976. Retention and degradation of ${ }^{125}$ I-insulin by perfused livers from diabetic rats. J. Clin. Invest. 57: 885-896.

37. Terris, S., and D. F. Steiner. 1975. Binding and degradation of ${ }^{125}$ I-insulin by rat hepatocytes. J. Biol. Chem. 250:8384-8389.

38. Freychet, P., R. Kahn, J. Roth, and D. M. Neville, Jr. 1972. Insulin interaction with liver plasma membranes. Independence of binding of the hormone and its degradation. J. Biol. Chem. 247:3953-3961.

39. Crofford, O. B. 1968. The uptake and inactivation of native insulin by isolated fat cells. J. Biol. Chem. 243:362-369.

40. Kaplan, S. A., J. W. Morris, M. D. Davidson, L. E. Gershenson, and M. Scott. 1976. Triacetylated insulin: biologic activity and resistance to degradation. Metabolism. 25:1209-1216.

41. Krupp, M. N., and J. N. Livingston. 1980. The binding and degradation of insulin by rat liver membranes: demonstration of three distinct insulin-binding components in detergent-solubilized material from liver plasma membrane. Endocrinology. 106:179-184.

42. LeCam, A., F. Maxfield, M. Willingham, and I. Pastan. 1979. Insulin stimulation of amino acid transport in isolated rat hepatocytes is independent of hormone internalization. Biochem. Biophys. Res. Commun. 88:873-881.

43. Marshall, S., and J. M. Olefsky. 1980. The endocytotic-internalization pathway of insulin metabolism: Relationship to insulin degradation and activation of glucose transport. Endocrinology. 107:19371945.

44. Parrilla, R., M. N. Goodman, and C. J. Toews. 1974. Effect of glucagon insulin ratios on hepatic metabolism. Diabetes. 23:725-731.

45. Cherrington, A. D., J. L. Chiasson, J. E. Lilljenquist, A. S. Jennings, U. Keller, and W. W. Lacy. 1976. The role of insulin and glucagon in the regulation of basal glucose production in the postabsorptive dog. J. Clin. Invest. 58:1407-1418.

46. DeFronzo, R. A., J. Tobin, and R. Andres. 1979. Glucose clamp technique: a method for quantifying insulin secretion and resistance. Am. J. Physiol. 237:E214-E223.

47. Ishida, T., Z. Chap, J. Chou, R. Lewis, C. Hartley, M. Entman, and J. Field 1983. Differential effects of oral, peripheral, intravenous, 
and intraportal glucose on hepatic glucose uptake and insulin and glucagon extraction in conscious dogs. J. Clin. Invest. 72:590-601.

48. Gorus, F. K., W. J. Malaisse, and D. G. Pipeleers. 1984. Differences in glucose handling by pancreatic A- and B-cells. J. Biol. Chem. 259:1196-1200.

49. Unger, R. H. 1983. Insulin-glucagon relationships in the defense against hypoglycemia. Diabetes. 32:575-583.

50. Maruyama, H., A. Hisatomi, L. Orci, G. M. Grodsky, and R. H. Unger. 1984. Insulin within islet is a physiologic glucagon release inhibitor. J. Clin. Invest. 74:2296-2299.

51. McCulloch, D. K., P. K. Raghu, D. J. Koerker, L. J. Klaff, and J. P. Palmer. 1985. Recognition of hypo- and hyperglycemia by the pancreatic A-cells is dependent on the B-cell. Clin. Res. 33:64a (Abstr.).

52. Bolli, G., P. DeFeo, G. Perriello, S. DeCosmo, P. Compagnucci,
F. Santeusanio, P. Brunetti, and R. H. Unger. 1984. Mechanism of glucagon secretion during insulin-induced hypoglycemia in man: role of the beta cell and arterial hyperinsulinemia. J. Clin. Invest. 73:917-922.

53. Mezey, E., T. D. Reisine, M. J. Brownstein, M. Palkovits, and J. Axelrod. 1984. $\beta$-Adrenergic mechanism of insulin-induced adrenocorticotropin release from anterior pituitary. Science (Wash. DC). 226: 1085-1086.

54. Histomi, A., H. Maruyama, L. Orci, M. Vasko, and R. H. Unger. 1985. Adrenergically mediated intrapancreatic control of the glucagon response to glucopenia in the isolated rat pancreas. J. Clin. Invest. 75: 420-426.

55. Eigler, N., L. Sacca, and R. S. Sherwin. 1979. Synergistic interactions of physiologic increments of glucagon, epinephrine, and cortisol in the dog. A model for stress-induced hyperglycemia. J. Clin. Invest. 63:114-123. 